\title{
UNIVALENCY AND STARLIKENESS OF NORMALIZED HURWITZ-LERCH ZETA FUNCTION INSIDE UNIT DISK
}

\author{
DeEPaK BAnsal AND JANusz SoKó
}

Abstract. In the present investigation we study normalized Hurwitz-Lerch Zeta function and find sufficient conditions, so that the normalized Hurwitz-Lerch Zeta function have certain geometric properties like close-to-convexity, univalency and starlikeness inside the unit disc.

Mathematics subject classification (2010): 30C45.

Keywords and phrases: analytic function, univalent function, starlike function, close-to-convex function, Hurwitz-Lerch Zeta function, polylogarithmic function.

\section{REFERENCES}

[1] Á. BARICZ, Geometric properties of generalized Bessel functions, Publ. Math. Debrecen 73 (2008), $155-178$.

[2] Á. BARICZ And S. PoOnus Amy, Starlikeness and convexity of generalized Bessel functions, Integral Transform. Spec. Funct. 21 (9) (2010), 641-653.

[3] Á. BARICZ, P. A. KUPÁN, AND R. SzÁsz, The radius of starlikeness of normalized Bessel function of first kind, Proc. Amer. Math. Soc. 142 (6) (2014), 2019-2025.

[4] L. Brickman, T. M. MacGregor, D. R. Wilken, Convex hulls of some classical families of univalent functions, Trans. Amer. Math. Soc. 156 (1971), 91-107.

[5] P. L. Duren, Univalent Functions, Grundlehren der Mathematischen Wissenschaften, Band 259, Springer-Verlag, New York, Berlin, Heidelberg and Tokyo, 1983.

[6] L. FÉJER, Untersuchungen über Potenzreihen mit mehrfach monotoner Koeffizientenfolge, Acta Literarum Sci. 8 (1936), 89-115.

[7] S. OZAKI, On the theory of multivalent functions, Sci. Rep. Tokyo Bunrika Daigaku A2 (1935), 167188.

[8] K. PIEJKo, J. SoKóŁ, On the convolution and subordination of convex functions, Appl. Math. Letters 25 (2012), 448-453.

[9] S. Ponnusamy, Close-to-convexity properties of Gaussian hypergeometric functions, J. Comput. Appl. Maths. 88 (1997), 327-337.

[10] S. Ponnusamy AND M. VuORInen, Univalence and convexity properties for gaussian hypergeometric functions, Rocky Mountain J. Math. 31 (1) (2001), 327-353.

[11] St. Ruscheweyh And V. Singh, On the order of starlikeness of hypergeometric functions, J. Math. Anal. Appl. 113 (1986), 1-11.

[12] H. M. Srivastava, J. CHOI, Zeta and q-Zeta Functions and Associated Series and Integrals, Elsevier, Amsterdam (2012).

[13] St. Rusheweyh, New criteria for univalent functions, Proc. Amer. Math. Soc. 49 (1975), 109-115.

[14] H. S. WiLf, Subordinating factor sequences for convex maps of the unit circle, Proc. Amer. Math. Soc. 12 (1961), 689-693. 